\title{
Suspected Resistance against Moxidectin in Sheep Strongylid Nematodes in Austria
}

\author{
Julia Schoiswohl ${ }^{1}$, Barbara Hinney ${ }^{2}$, Alexander Tichy ${ }^{3}$, Karl Bauer ${ }^{4}$, Anja Joachim ${ }^{2}$ and Reinhild \\ Krametter-Frötscher ${ }^{1}$ \\ 1. Department for Farm Animals and Veterinary Public Health, University of Veterinary Medicine Vienna, Vienna 1210, Austria \\ 2. Department of Pathobiology, Institute of Parasitology, University of Veterinary Medicine Vienna, Vienna 1210, Austria \\ 3. Bioinformatics and Biostatistics Platform, University of Veterinary Medicine Vienna, Vienna 1210, Austria \\ 4. Animal Health Service Styria, Graz 8010, Austria
}

\begin{abstract}
Loss of efficacy due to resistance development against anthelmintics in livestock parasites is a growing concern worldwide. The aim of the present study was to determine the efficacy of moxidectin, a frequently-used macrocyclic lactone, against gastrointestinal nematodes of sheep in Austria. Individual faecal samples were collected from 243 adult sheep from 16 flocks in Styria and Salzburg before deworming and egg excretion (EPG (eggs per gram) of faeces) was determined using a modified McMaster technique. The animals were randomly assigned to a treatment group which received $0.2 \mathrm{mg} / \mathrm{kg}$ of body weight of moxidectin (Cydectin $^{\circledR}$, Zoetis Schweiz GmbH, Zürich, Switzerland), and an untreated control group. Fourteen days after deworming a FECRT (faecal egg count reduction test) for detection of anthelmintic resistance was performed. Before deworming, the infection rate for gastrointestinal strongylids was $94.7 \%$, with EPG values of 0 5,800. The FECRT showed reduction rates between $93.08 \%$ and $99.78 \%$ and was sufficient in 15/16 flocks. The lower confidence interval was 70.0 100\%. In 3/16 flocks this value was below the minimum for sufficient efficacy $(70.0 \%, 79.0 \%, 85.0 \%)$, and in two flocks the value $(90.0 \%)$ was near the limit. These results indicated a (suspected) reduced efficacy of moxidectin in $5 / 16$ examined flocks.
\end{abstract}

Key words: FECRT (faecal egg count reduction test), EPG (eggs per gram) faeces, moxidectin, anthelmintic resistance.

\section{Introduction}

Infections with GIS (gastrointestinal strongylids), nematodes of the order Strongylida which parasitise the gastrointestinal tract (stomach and intestines) of animals and humans, are one of the most prevalent health issues affecting small ruminants worldwide [1]. Common clinical signs of GIS infections are associated with anorexia, diarrhoea and emaciation [2] and a high worm burden may even lead to the death of an infected animal [3]. Such infections are not only associated with morbidity and mortality but also with production losses [4]. Currently, the control of GIS is largely based on the use of different groups of commercially available anthelmintics. Especially modern broad-spectrum anthelmintic drugs are being widely used for treatment,

Corresponding author: Julia Schoiswohl, Mag.Med.Vet., Resident ECSRHM, research field: small ruminants. but also for metaphylaxis [4]. Over the past decades, resistance to anthelmintic drugs has become a major problem, particularly in small ruminants.

Anthelmintic resistance is defined as a genetic variation in parasites to survive treatment with recommended doses of the used anthelmintic drug. As a consequence of selective pressure exerted by treatment, resistant strains of helminths can develop. Resistant populations are able to survive the toxic effects of drugs after repeated administration [4].

Resistance among GIS infecting sheep has been reported since the early 1980s, especially in South Africa, Latin America, Australia and New Zealand [4]. The earliest reports refer on resistance to benzimidazoles and imidazoles [5]. Some years later, resistance to ML (macrocyclic lactones) was recorded and increased over the years [6]. Nowadays 
cross-resistance between different groups of anthelmintics and multi-drug resistant populations (resistant against two or more groups of anthelmintic drugs) are becoming more and more frequent $[4,7]$.

In many European countries, many recent reports on anthelmintic resistance in sheep strongylids refer to benzimidazoles, but the number of cases of resistance to $\mathrm{ML}$ is also increasing [8]. In Switzerland, a country similar to Austria in its geographical and agriculture structure, the first case of an avermectin resistance was reported from a flock of goats on a small farm near Zurich where a goat was imported from South Africa [9]. After this finding, Artho et al. [10] investigated the occurrence of avermectin-resistant GIS populations in sheep and goats in Switzerland. According to the FECRT (faecal egg count reduction test) resistant GIS populations were confirmed in seven out of 24 Boer goat farms and in two out of 12 Dorper sheep farms. A further eight goat farms and six sheep farms were suspected of resistance [10]. ML resistance in sheep strongylids has also been described from Slovakia [11], the Netherlands [12] and Germany [13]. In addition, multi-drug resistant populations of GIS were detected in Italy [14, 15], Germany [16] and Scotland [17-19].

Problems with anthelmintic resistance and its rapid spread have spurred research on and development of different techniques for its detection.

The FECRT is a widely used in vivo technique and recommended by the WAAVP (World Association for the Advancement of Veterinary Parasitology) [20]. With this test the reduction of excreted strongylid EPG (eggs per gram) of faeces 10 14 days after application of an anthelmintic drug compared to the excretion prior to treatment is evaluated. For an adequate efficacy of the used anthelmintic the reduction in EPG has to be $>95 \%$ and the lower confidence interval has to be $>90 \%$. In detail this technique is described in the guidelines of the WAAPV [21].

In Austria, few local data regarding benzimidazole resistance in sheep strongylids are documented [22].
Feichtenschlager et al. [23] suspected doramectin resistance in one out of four sheep flocks investigated. However, data of these investigations have to be seen critical because animals were treated without body weight determination, so underdosing may have occurred. Currently, no detailed investigations on ML resistance in strongylids of small ruminants in Austria have been published so far. The aim of the present study was to determine the efficacy of moxidectin, a frequently used ML, against gastrointestinal strongylids of sheep from different flocks from Austria as the follow-up to a pilot study on the presence and seasonal dynamics of strongylid infections in sheep in the investigated area [24].

\section{Animals, Materials and Methods}

This investigation was approved by the institutional ethics and animal welfare committee of the Vetmeduni Vienna in accordance with good scientific practice guidelines and national legislation. Parts of results of this investigation are already published in Ref. [24].

Adult animals (ewes) from 16 farms in Styria (number $n=13$ ) and Salzburg $(n=3)$, two federal states of Austria, were examined between March and September 2015. They were pastured with their lambs on communal alpine pastures in Styria during summertime (May to September). In total, 243 adult sheep, identifiable by individual earmarks, were enrolled in the study.

During the farm visits, information about worm management and anthelmintic treatment was collected. Individual faecal sample were taken directly from the rectum of all sheep before deworming. Ewes of the flocks larger than 30 animals were randomly assigned by ear tag numbers to a treatment and a control group (15 ewes each); animals from smaller flocks were all assigned to the treatment group. All sheep were weighed and animals from the treatment group were treated with $0.2 \mathrm{mg} / \mathrm{kg}$ bodyweight of the ML moxidectin (Cydectin ${ }^{\circledR}$, Zoetis Schweiz GmbH, Zürich, Switzerland) according to their exact body weight. In 
total the treatment group consisted of 212 sheep and the control group of 31 sheep (from two different farms). Fourteen days after treatment, individual faecal sample were collected directly from the rectum.

For the detection of $\mathrm{ML}$ resistance, a FECRT according to the recommendations of the WAAVP [20] was performed. The percentage reduction and the lower confidence interval were calculated [25]. In herds with a treatment and a control group, data were additionally analysed with the methods described by Presidente [26], Dash et al. [27] and Coles et al. [20, 21].

All samples were analysed by a flotation technique and quantitatively by a modified McMaster counting technique with a lower detection limit of 50 EPG. Values were classified into four categories: EPG-values between 0 and 49 were categorised "negative because of the detection limit", values between 50 and 450 were categorised as "slight infection", values between 500 and 1,000 were categorised as "moderate infection" and FECs $>1,000$ EPG were considered indicative of "heavy infections" [28].

In addition third-stage larvae of nematodes (L3) were cultivated and identified according to Van Wyk and Mayhew [29] in pooled flock samples (one from each farm) before communal alpine pasturing and at the end of the grazing season to determine the presence of different genera of strongylid nematodes.

\section{Statistical Analysis}

Descriptive and inferential statistics were calculated using Microsoft ${ }^{\circledR}$ Excel 2010 and IBM SPSS Statistics (Version 20.0). Correlations were performed by calculating Spearman's correlation coefficient. For all analyses a $p$-value $<0.05(5 \%)$ was seen as significant. The percentage of reduction and the lower confidence interval was calculated using BootStreat $^{\circledR}$ (INRA Centre de Tours, version: 1.0.0.0. created: 22.3.2013).

\section{Results}

\subsection{Management Questionnaire}

Both smallholder farms with a few animals
(Farms 5-9, 11, 14) and full-time professional farms (Farms 1-4, 10, 12, 13, 15, 16) were enrolled. The smallest farm had six and the largest one 140 ewes. Animals from the individual farms were pastured together for years on an alpine pasture during summertime. All sheep were dewormed minimum once per year in spring. On 10 farms $(1,2,4,7,9-14)$ anthelmintic treatment was applied twice a year, in spring and in autumn. On farm 6 treatments were applied on demand, minimum three times a year (Tables 1 and 2).

\subsection{EPG Values before Deworming}

As determined in the previous study, the prevalence of strongylid infections based on faecal egg count was 94.7\% (230/243). The EPG values ranged between 0 and 5,800 (mean 508.69; standard deviation 713.351). Thirteen animals $(5.3 \%)$ showed values $<50$ EPG, 158 sheep EPG values between 50 and 450, 40 animals (16.5\%) showed values between 500 and 1,000 and 32 sheep (13.2\%) show values $>1,000$ EPG [24] (Fig. 1).

\subsection{Differentiation of Strongylid Larvae}

Trichostrongylus spp. and Haemonchus contortus were the most dominant of all identified L3 in spring before deworming and also in autumn after communal alpine pasturing. $H$. contortus significantly increased from the start of communal alpine pasturing to examination at the end of the grazing season $(p=0.005)$, while Trichostrongylus spp. showed a significant decrease between the two sampling times $(p=0.004)$. Details on prevalences determined during the grazing season are given in Ref. [24] (Fig. 2).

\subsection{EPG Values after Deworming}

Fourteen days after deworming 182 animals (85.9\%) showed values $<50$ EPG and $30(14.2 \%)$ animals showed EPG values between 50 and 450 [24] (Fig. 1).

\subsection{Egg Count Reduction and Lower Confidence Intervals}

The fecal egg count reduction after deworming 


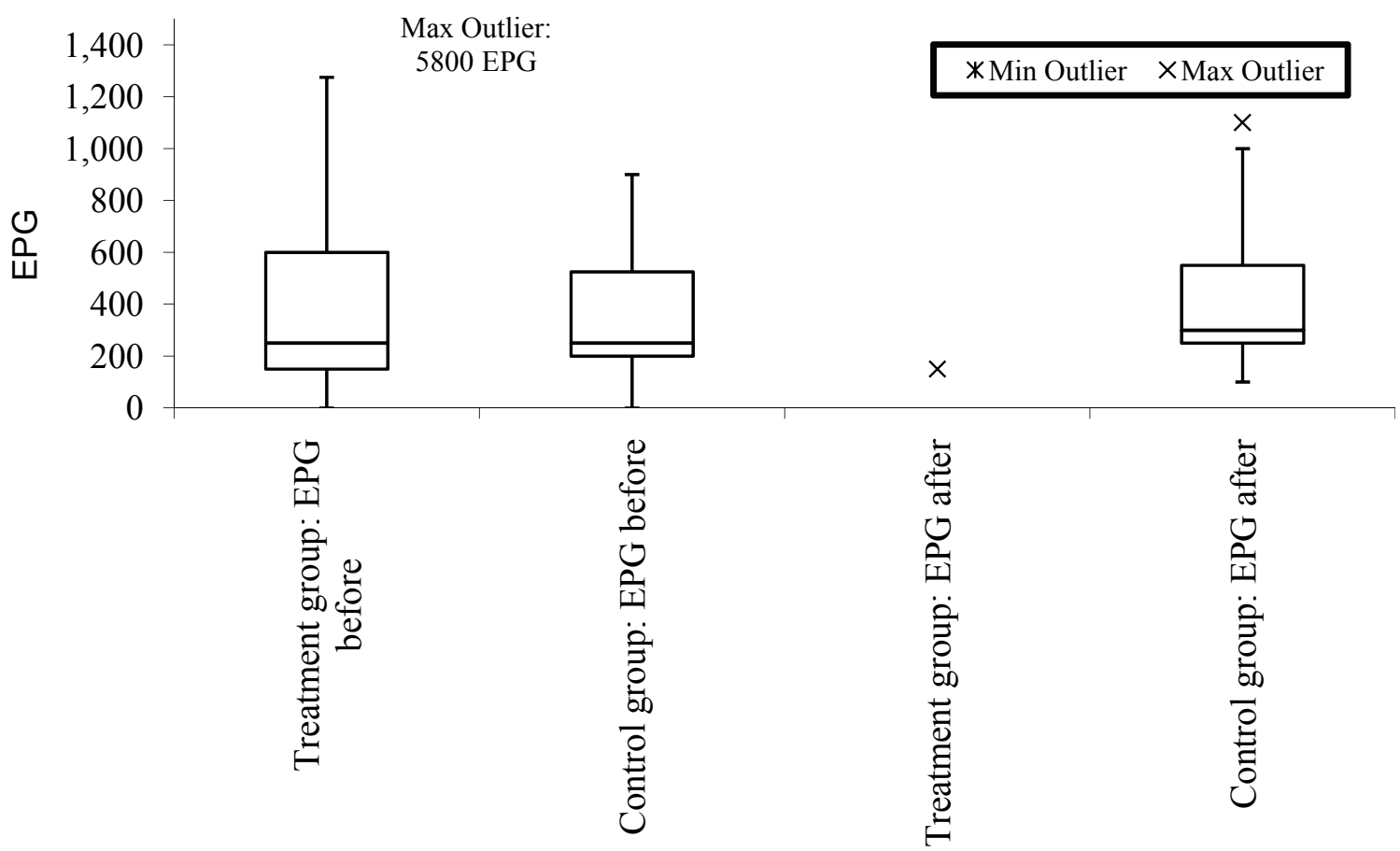

Fig. 1 EPG-values before and after deworming.

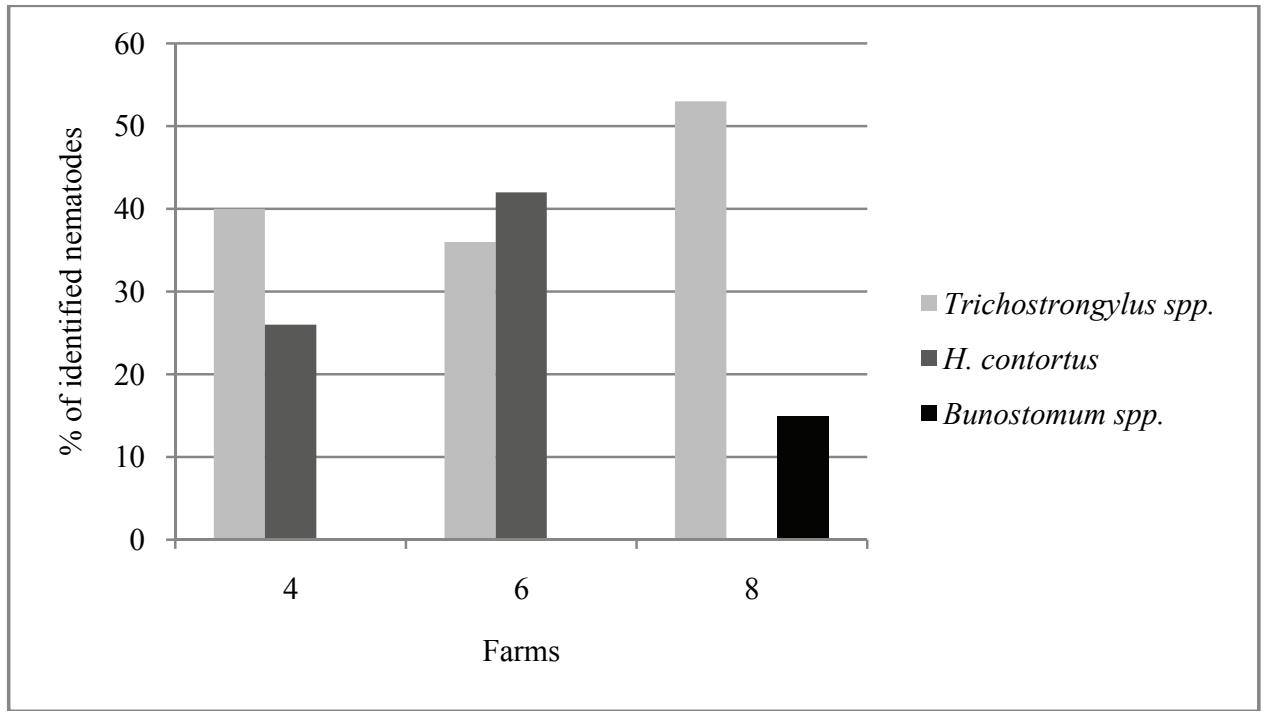

Fig. 2 Most common nematode taxa (\%) on farms with a suspected of reduced efficacy (Farms 4, 6 and 8).

ranged between $93.1 \%$ and $99.8 \%$. In one herd, the reduction was insufficient with $93.1 \%$. The other 15 herds showed values between $95.5 \%$ and $99.8 \%$.

The lower confidence interval ranged between $70.0 \%$ and $100 \%$. In three of 16 herds the value was below the value considered sufficient for efficacy $(70.0 \%, 79.0 \%$ and $85.0 \%$ ), and in two herds the value $(90.0 \%)$ was on the limit (Fig. 1).

\section{Discussion}

The aim of the study was to evaluate the efficacy of moxidectin in a formulation registered for the use in sheep $\left(\right.$ Cydectin $^{\circledR}$, Zoetis Schweiz GmbH, Zürich, Switzerland) in several sheep flocks from alpine regions of Austria.

A high prevalence of GIN infections in sheep could 
be determined in this study. No flock was free from strongylid nematode infections and the intra-flock prevalences were very high with $70.0 \% \sim 100 \%$. These results are in line with the results of previous studies from Austria [23, 30, 31] and comparable to countries like Germany [32-35].

The study design in this trial followed the recommendations by Coles et al. [21] on the detection of anthelmintic resistance in strongylid nematodes of sheep. The post-treatment investigation was performed 14 days after the anthelmintic treatment which is recommended for the evaluation of ML efficacy in sheep. The detection technique used in the present study was the McMaster counting technique which is a method for the detection of reduced efficacy. The precision of the quantification of egg excretion according to McMaster, increase with increasing egg numbers and the FECRT can underestimate the occurrence of anthelmintic resistance when the overall OPG values are low [36]. In this investigation the baseline EPG values prior treatment were high and remained so in the control group with only 13 animals $(5.34 \%)$ with low values $(\mathrm{EPG}<50)$.

In this study, animals from farms with different management systems were included, on the one hand smallholder farms with few animals and on the other hand professional farms were sheep were kept for economic reasons. All five farms with a (suspected) reduced efficacy are smallholder farms and the management, especially the anthelmintic treatment regime, was poorly organised. Anthelmintic drugs were underdosed and as consequence of this and the long-practiced "dose and move system" the missing refugium of an adequate level of susceptible worms is the most likely reason for the development of resistance. Three of these five farms had used moxidectin for five years in a row once or twice a year; however, other farms with a good efficacy had a the same treatment scheme so no clear pattern for management practices that could promote resistance in the examined herd was detected. Other factors may also contribute to the development of a resistant worm population in a herd. Resistance does not always arise primarily in smallholder management systems; in South Africa anthelmintic resistance is primarily reported from large-scale commercial and institutional farms, although resource-poor smallholder farms are also affected [37]. Resistance prevalence in Europe is reported at much lower levels compared to other parts of the world [38-40]. The prevalence of ivermectin resistance remains relatively low in Europe and there are only few documented reports of moxidectin resistance in small ruminants. Schnyder et al. [9] reported the first avermectin resistance from Switzerland. Boer goats had been imported from South Africa and on the farm of origin resistance to mebendazole and ivermectin was present in $H$. contortus. Upon investigation of the Swiss flock, moxidectin showed only $96 \%$ reduction in the FECRT. After this report, a wider investigation was conducted and avermectin resistance was detected in nine out of 36 farms and suspected for further 14 farms. $H$. contortus and Trichostrongylus spp. were the dominant species detected. The agricultural situation in Switzerland is comparable to that in Austria, and results from the present study show similar rates of resistant and suspected herds. In addition to the development of anthelminic resistance by false management practices, a high risk of importing resistant worm populations with imported animals from areas with widely spread resistance was descripted by Schnyder et al. [9]. Adequate quarantine is mandatory to minimize the danger of importing anthelmintic-resistant populations [41]. Communal alpine pasturing during summertime, like in the present study, is also a potential threat for dissemination of resistant worms to the individual farms since animals from different flocks share the summer pastures before returning to their individual lowland pastures before overwintering indoors. Despite the cold climate in the alpine areas of transhumance, increasing occurrence of $H$. contortus, the most dangerous strongylid worm of sheep both in terms of health and 
Table 1 Information on the enrolled flocks and the applied anthelmintic management practices.

\begin{tabular}{|c|c|c|c|c|c|}
\hline Farm No. & $\begin{array}{l}\text { Number of animals } \\
\text { enrolled in study }\end{array}$ & Management type & $\begin{array}{l}\text { Moxidectin use: duration/annual } \\
\text { frequency }\end{array}$ & $\begin{array}{l}\text { Reduction }(\%) \\
\left(95 \%{ }^{a}\right)\end{array}$ & $\begin{array}{l}\text { Lower confidence } \\
\text { interval }\left(90^{\mathrm{a}}\right)\end{array}$ \\
\hline 1 & 12 & full-time professional & $\begin{array}{l}3 \text { years without interruption, } 2 x / \text { year, } \\
\text { in spring and autumn }\end{array}$ & 97.69 & 92.00 \\
\hline 2 & 23 & full-time professional & $\begin{array}{l}5 \text { years without interruption, } 2 x / \text { year, } \\
\text { in spring and autumn }\end{array}$ & 99.67 & 99.00 \\
\hline $3^{b}$ & 31 & full-time professional & $\begin{array}{l}3 \text { years without interruption/ once per } \\
\text { year in spring }\end{array}$ & 99.77 & 100 \\
\hline 4 & 15 & full-time professional & $\begin{array}{l}5 \text { years without interruption, } 2 x / \text { year, } \\
\text { in spring and autumn }\end{array}$ & 93.08 & 79.00 \\
\hline 5 & 10 & smallholder & $\begin{array}{l}5 \text { years without interruption, } 1 \mathrm{x} / \text { year } \\
\text { in spring }\end{array}$ & 96.94 & 90.00 \\
\hline 6 & 6 & smallholder & $\begin{array}{l}2 \text { years without interruption, applied } \\
\text { on demand, minimum } 3 \mathrm{x} / \mathrm{year}\end{array}$ & 95.50 & 85.00 \\
\hline 7 & 10 & smallholder & $\begin{array}{l}2 \text { years without interruption/ } 2 x / y e a r, \\
\text { in spring and autumn }\end{array}$ & 98.86 & 95.00 \\
\hline 8 & 10 & smallholder & $\begin{array}{l}2 \text { years without interruption/ 1x/year in } \\
\text { spring }\end{array}$ & 97.96 & 70.00 \\
\hline 9 & 10 & smallholder & $\begin{array}{l}5 \text { years without interruption/ } 2 x / \text { year, } \\
\text { in spring and autumn }\end{array}$ & 96.48 & 90.00 \\
\hline 10 & 13 & full-time professional & $\begin{array}{l}\text { first time/ } 2 x / y e a r \text {, in spring and } \\
\text { autumn }\end{array}$ & 98.23 & 93.00 \\
\hline 11 & 10 & smallholder & $\begin{array}{l}5 \text { years without interruption/ } 2 x / \text { year, } \\
\text { in spring and autumn }\end{array}$ & 98.95 & 97.00 \\
\hline $12^{\mathrm{b}}$ & 30 & full-time professional & $\begin{array}{l}3 \text { years without interruption/ } 2 \mathrm{x} / \text { year, } \\
\text { in spring and autumn }\end{array}$ & 99.72 & 100 \\
\hline 13 & 15 & full-time professional & $\begin{array}{l}5 \text { years without interruption/ } 2 x / \text { year, } \\
\text { in spring and autumn }\end{array}$ & 98.66 & 95.00 \\
\hline 14 & 9 & smallholder & $\begin{array}{l}2 \text { years without interruption/ } 2 x / \text { year, } \\
\text { in spring and autumn }\end{array}$ & 99.33 & 99.00 \\
\hline 15 & 18 & full-time professional & $\begin{array}{l}3 \text { years without interruption/ once per } \\
\text { year in spring }\end{array}$ & 99.53 & 99.00 \\
\hline 16 & 21 & full-time professional & $\begin{array}{l}5 \text { years without interruption/ once per } \\
\text { year in spring }\end{array}$ & 98.05 & 95.00 \\
\hline
\end{tabular}

avalues less than the minimum required for good efficacy;

${ }^{b}$ flocks with two groups (treatment and control); percent egg output reduction and lower confidence intervals after deworming (calculations according to Kocherpakdee et al. [25]).

Table 2 Percent reduction and lower confidence intervals of the FECR on farms with a treatment and a control group [20, 21, 25-27].

\begin{tabular}{lllll}
\hline \multirow{2}{*}{ Control groups } & \multicolumn{2}{c}{ Reduction (\%) } & \multicolumn{2}{c}{ Lower confidence interval } \\
\cline { 2 - 3 } \cline { 5 - 5 } & Farm 3 & Farm 12 & Farm 3 & Farm 12 \\
\hline Kochapakdee et al. [25] & 99.8 & 99.7 & 100 & 100 \\
Coles et al. [20, 21] & 99.8 & 99.8 & 100 & 100 \\
Dash et al. [27] & 99.8 & 99.8 & 100 & 100 \\
Presidente [26] & 99.7 & 99.8 & 99.0 & 100 \\
\hline
\end{tabular}

development of anthelmintic resistance, has recently been suspected [24], indicating the urgent need for monitoring management of resistance.

On-farm management practices that seem to promote the development of anthelmintic resistance as gathered from the questionnaire include high treatment rates and prolonged application of the same anthelmintic drug for several years. The observed differences in the rates and patterns of resistance development illustrate that management measures to prevent the development of anthelmintic resistance must be well organised and tailored to each management system or farm. This potentially complicates the communication between farmers and 
veterinarians and training for resistance management and prevention. The most important thing is to sustain an adequate level of refugia with susceptible GIS [42]. This can be achieved through maintaining an adequate pasture infection pressure or leaving some of the animals in the flock untreated. TST (targeted selective treatment) has been proposed as a method to reduce GIN infections in sheep and to limit the selective pressure that leads to anthelmintic resistance [43]. The downside of TST is that identification of the individual animals to be treated is required, and practitioners and farmers or veterinarians often consider this as unpractical. None of the investigated farms practised TST because of the supposed additional expenditure.

The study presented here showed that resistance against moxidectin must be suspected in sheep strongylids in Austria. Local veterinarians and farmers have to be aware that a change in the management of nematode infections is necessary to prevent an increase of ML resistance in the Austrian sheep population. However, further studies are needed from other regions in Austria to obtain more information regarding the prevalence of ML resistance in small ruminants in Austria. The FECRT can be used to estimate the extent of resistance in the field, and the inclusion of an untreated control group is not mandatory since estimates for reduction and lower confidence intervals were similar using different models of calculation as shown for the farms where control groups could be included.

Since the nematode species distribution on three of the examined farms with suspected moxidectin resistance varied to a certain extent, larval cultures should be provided before and after treatment for hers with a reduced efficacy to determine the prevalent nematode taxa that might contribute to it.

\section{Conclusions}

The present study describes a high individual $(94.66 \%)$ and flock (100\%) infection rate with strongylid nematodes of sheep and the first occurrence of (suspected) moxidectin resistance in flocks in Austria. In course of the findings from this investigation, anthelmintic resistance seem to be an increasing problem. Veterinarians and farmers have to be aware that a change in the management of nematode infections is necessary to prevent an increase of ML resistance in the Austrian sheep population. For example, TST has been proposed as an effective method to reduce GIN infections and to limit the selective pressure that leads to anthelmintic resistance.

Further studies are warranted to closely monitor the situation and to develop appropriate countermeasures to prevent the increase and spread on anthelmintic resistance in sheep nematodes in Austria and the alpine regions of Central Europe.

\section{Acknowledgments}

The authors acknowledge the dedicated assistance of the sheep breeders and the local veterinarians and the Animal Health Service Styria for the financial support.

\section{Conflict of interest}

The authors whose names are listed certify that they have no affiliations with or involvement in any organization or entity with any financial interest or non-financial interest in the subject matter or materials discussed in this manuscript.

\section{References}

[1] Hertzberg, H., and Sager, H. 2006. "Problems of Helminth Infestation in Domestic Ruminants in Switzerland: Current Perspectives." Schweiz. Arch. Tierheilk 148: 511-21. (in Germany)

[2] Steel, J. W., Jones, W. O., and Symons, L. E. A. 1982. "Effects of a Concurrent Infection of Trichostrongylus colubriformis on the Productivity and Physiological and Metabolic Responses of Lambs Infected with Ostertagia circumcincta." Aust. J. Agr. Res. 33: 131-40.

[3] Crab, N. W., Noppe, W., Pelicaen, C., Van Hoorelbeke, K., and Deckmyn, H. 2002. "The Parasitic Hematophagous Worm Haemonchus contortus Inhibits Human Platelet Aggregation and Adhesion: Partial Purification of a Platelet Inhibitor." Thromb Haemost 87: 899-904. 
[4] Várady, M., Papadopoulos, E., Dolinská, M., and Königová, A. 2011. "Anthelmintic Resistance in Parasites of Small Ruminants: Sheep Versus Goats." Helminthologia 48: 137-44.

[5] Overend, D. J., Phillips, M. L., Poulton, A. L., and Foster, C. E. 1994. "Anthelmintic Resistance in Australian Sheep Nematode Populations." Aust. Vet. J. 71: 117-21.

[6] Besier, B. 2007. "New Anthelmintics for Livestock: The Time Is Right." Trends Parasitol 23: 21-4.

[7] Van Wyk, J. A., Stenson, M. O., Van der Merwe, J. S., Vorster, R. J., and Viljoen, P. G. 1999. "Anthelmintic Resistance in South Africa: Surveys Indicate an Extremely Serious Situation in Sheep and Goat Farming." Onderstep J. Vet. Res. 66: 273-84.

[8] Papadopoulos, E. 2008. "Anthelmintic Resistance in Sheep Nematodes.” Small Rum. Res. 76: 99-103.

[9] Schnyder, M., Torgerson, P. R., Schönmann, M., Kohler, L., and Hertzberg, H. 2005. "Multiple Anthelmintic Resistance in Haemonchus contortus Isolated from South African Boer Goats in Switzerland." Vet. Parasitol. 128: 285-90.

[10] Artho, R., Schnyder, M., Kohler, L., Torgerson, P. R., and Hertzberg, H. 2007. "Avermectin-Resistance in Gastrointestinal Nematodes of Boer Goats and Dorper Sheep in Switzerland." Vet. Parasitol 144 (1-2): 68-73.

[11] Cernanska, D., Várady, M., and Čorba, J. 2006. “A Survey on Anthelmintic Resistance in Nematode Parasites of Sheep in the Slovak Republic." Vet. Parasitol 135: 39-45.

[12] Borgsteede, F. H., Pekelder, J. J., Dercksen, D. P., Sol, J., Vellema, P., Gaasenbeek, C. P., and Van der Linden, J. N. 1997. "A Survey of Anthelmintic Resistance in Nematodes of Sheep in the Netherlands." Vet. Q. 19: 167-71.

[13] Scheuerle, M. C., Mahling, M., and Pfister, K. 2009. "Anthelminthic Resistance of Haemonchus Contortus in Small Ruminants in Switzerland and Southern Germany." Wien Klin Wochenschr 121: 46-9.

[14] Traversa, D., Paoletti, B., Otranto, D., and Miller, J. 2007. "First Report of Multiple Drug Resistance in Trichostrongyles Affecting Sheep under Field Conditions in Italy." Parasitol. Res. 101: 1713-6.

[15] Traversa, D., Iorio, R., Klei, T. R., Kharchenko, V. A., Gawor, J., Otranto, D., et al. 2007. "New Method for Simultaneous Species-Specific Identification of Equine Strongyles (Nematoda, Strongylida) by Reverse Line Blot Hybridization.” J. Clin. Microbiol. 45: 2937-42.

[16] Voigt, K., Scheuerle, M., Hamel, D., and Pfister, K. 2012. "High Perinatal Mortality Associated with Triple Anthelmintic Resistance in a German Sheep Flock." Tierarztl. Prax. Ausg. G Grosstiere Nutztiere 40: 107-11.

[17] Bartley, D. J., Jackson, F., Jackson, E., and Sargison, N. 2004. "Characterisation of Two Triple Resistant Field
Isolates of Teladorsagia from Scottish Lowland Sheep Farms." Vet. Parasitol 123: 189-99.

[18] Sargison, N. D., Jackson, F., Bartley, D. J., and Moir, A. C. P. 2005. "Failure of Moxidectin to Control Benzimidazole-, Levamisole- and Ivermectin-Resistant Teladorsagia circumcinta in a Sheep Flock." Vet. Rec. 156: 105-9.

[19] Sargison, N. D., Scott, P. R., Wilson, D. J., Macrae, A. I., and Penny, C. D. 2010. "Teladorsagia circumcincta Resistance to Moxidectin and Multiple Anthelmintic Groups in Ewes Following Use of the Persistent Drug before Lambing." Vet. Rec. 16: 523-7.

[20] Coles, G. C., Bauer, C., Borgsteede, F. H., Geerts, S., Klei, T. R., Taylor, M. A., et al. 1992. "World Association for the Advancement of Veterinary Parasitology (W.A.A.V.P.) Methods for the Detection of Anthelmintic Resistance in Nematodes of Veterinary Importance." Vet Parasitol 44: 35-44.

[21] Coles, G. C. Jackson, F., Pomroy, W. E., Prichard, R. K., Von Samson-Himmelstjerna, G., Silvestre, A., et al. 2006. "The Detection of Anthelmintic Resistance in Nematodes of Veterinary Importance.” Vet. Parasitol 136: 167-85.

[22] Hertzberg, H., and Bauer, C. 2000. "Anthelmintic Resistance in Gastrointestinal Strongylidae in Sheep and Goats: New Data on Prevalence, Epidemiology, Preventive Measures and Alternatives to Anthelmintic Drugs." Berl Munch Tierarztl Wochenschr 113: 122-8.

[23] Feichtenschlager, C., Hinney, B., Klose, S., Tichy, A., Tix, A., Strobl, L., et al. 2014. "Occurrence of Helminths in Small Ruminant of Styria and Special Consideration of the Effectiveness of Benzimidazoles and Macrocyclic Lactones." Tierärztl. Mschr. 101: 251-62. (in Germany)

[24] Schoiswohl, J., Joachim, A., Hinney, B., Tichy, A., Bauer, K., Stanitznig, A., et al. 2017. "Influence of Communal Alpine Pasturing in Styria, Austria, on the Development of Gastrointestinal Strongylid Infections over the Grazing Season in Sheep-A Pilot Study." Berl Münch Tierärztl Wochenschr. (in press)

[25] Kochapakdee, S., Pandey, V. S., Pralomkarn, W., Choldumrongkul, S., Ngampongsai, W., and Lawpetchara, A. 1995. "Anthelmintic Resistance in Goats in Southern Thailand." Vet. Rec. 137: 124-5.

[26] Presidente, P. J. A. 1985. "Methods for Detection of Resistance to Anthelmintics." In Resistance in Nematodes to Anthelmintics, edited by Anderson, N., and Waller, P. J. Glebe NSW: CSIRO Division of Animal Health, 13-28.

[27] Dash, K. M., Hall, E., and Barger, I. A. 1988. "The Role of Arithmetic and Geometric Worm Egg Counts in Faecal Egg Count Reduction Test and in Monitoring Strategic Drenching Programs in Sheep." Aust. Vet. J. 65: 66-8.

[28] Taylor, M. A. 2010. "Parasitological Examination in Sheep Health Management." Small Ruminant Research 92: 
120-5.

[29] Van Wyk, J. A., and Mayhew, E. 2013. "Morphological Identification of Parasitic Nematode Infective Larvae of Small Ruminants and Cattle: A Practical Lab Guide.” Onderstepoort J. Vet. 80: 1-14.

[30] Biermayer, W. 1996. "Untersuchungen zur Bestimmung der Resistenzsituation von ovinen Magen-Darmstrongyliden im Bundesland Salzburg." M.Sc. thesis, University of Veterinary Medicine Vienna.

[31] Gergely, A., and Wehowar, A. 2008. "Magen-Darm-Strongyliden in Ausgewählten Niederösterreichischen Schafherden: Vorkommen und Status von Anthelminthika-Resistenzen." Ph.D. thesis, University of Veterinary Medicine Vienna.

[32] Benesch, C. 1993. "Parasiten des Magen-Darm-Traktes von Schafen in Hessen: Eine Sektionsstudie.” M.Sc. thesis, University of Giessen.

[33] Grzonka, E., Kaulfuss, K. H., Schliephake, A., and Pfeifer, F. 2000. "Studies on Endoparasitic Infection in Sheep Flocks in Sachsen-Anhalt." Tierarztl Umsch 55: 658-662.

[34] Moritz, E. 2005. "Ein Beitrag zum Befall mit Endoparasiten und zum Nachweis von Benzimidazolresistenzen bei Magen-Darm- Strongyliden der Schafe in Niedersachsen.” M.Sc. thesis, Tieraerztliche Hochschule Hannover.

[35] Idris, A., Moors, E., Sohnrey, B., and Gauly, M. 2012. "Gastrointestinal Nematode Infections in German Sheep." Parasitol Res. 110: 1453-9.

[36] Levecke B., Rinaldi, L., Charlier, J., Maurelli, M. P., Bosco, A., Vercruysse, J., et al. 2012. "The Bias, Accuracy and Precision of Faecal Egg Count Reduction Test Results in Cattle Using McMaster,
Cornell-Wisconsin and FLOTAC Egg Counting Methods." Vet. Parasitol 188: 194-9.

[37] Vatta, A. F., and Lindberg, A. L. E. 2006. "Managing Anthelmintic Resistance in Small Ruminant Livestock of Resource-Poor Farmers in South Africa." J. S. Afr. Vet. Assoc. 77: 2-8.

[38] Höglund, J., Gustafsson, K., Ljungström, B. L., Engström, A., Donnan, A., and Skuce, P. 2009. "Anthelmintic Resistance in Swedish Sheep Flocks Based on a Comparison of the Results from the Faecal Egg Count Reduction Test and Resistant Allele Frequencies of the Beta-Tubulin Gene." Vet. Parasitol 161: 60-8.

[39] Mitchell, E. S. E., Hunt, K. R., Wood, R., and McLean, B. 2010. "Anthelmintic Resistance on Sheep Farms in Wales." Vet. Rec. 166: 650-2.

[40] Paraud, C., Pors, I., Rehby, L., and Chartier, C. 2010. "Absence of Ivermectin Resistance in a Survey on Dairy Goat Nematodes in France.” Parasitol. Res. 106: 1475-9.

[41] Kaplan, R. M., and Vidyashankar, A. N. 2012. An Inconvenient Truth: Global Worming and Anthelmintic Resistance.” Vet. Parasitol. 186 (1-2): 70-8.

[42] Van Wyk, J. A. 2001. "Refugia-Overlooked as Perhaps the Most Potent Factor Concerning the Development of Anthelmintic Resistance." Onder-Stepoort J. Vet. Res. 68: 55-67.

[43] Kenyon, F., McBean, D., Greer, A. W., Burgess, C. G., Morrison, A. A., Bartley, D. J., et al. 2013. "A Comparative Study of the Effects of Four Treatment Regimes on Ivermectin Efficacy, Body Weight and Pasture Contamination in Lambs Naturally Infected with Gastrointestinal Nematodes in Scotland.” Int. J. Parasitol.: Drugs Drug Resist. 3: 77-84. 